\title{
Decision Making: A Core Problem of Social Cognition
}

\author{
Auditi Pramanik ${ }^{1 *}$
}

\section{ABSTRACT}

Successful decision making involves our ability to understand the intensions, emotions and beliefs of other people. An important feature of decision making in a social setting concern the interaction of areas and Social cognition is an integral part of social psychology, which deals with the psychological mechanisms that mediate the individual's responses to the social environment. Notable to social cognitive theories are the ideas which are applied and extended to many concepts, theories, models and paradigms from cognitive psychology in social context. This approach leads to remarkable progress in understanding of social scenario, people's decisions and also offers insights into social issues. It helps to understand reactions of people in social context. Decision making is just one of the many areas in which social cognition has an important role. Decision making is a complex cognitive skill. Social cognition attempts to explain the broad social aspects of human experience, such as how decision making are influenced by the presence of others as well as the social situations in which they find themselves. This article presents a fundamental idea of social cognitive perspective of decision making process and factors that influence our decisions.

Keywords: Decision Making, Social Cognition, Rational Model, Attribution Theory, Cognitive Bias

In our everyday life very often we seek for others opinions on a particular matter before come to any decision or even sometimes unconsciously we go with the flow of our surrounding while making choices. This is because decisions are not made independently, as each decision point is influenced by information that is received from the society where we live. The social context thus often exerts an influence on our decisions because we have or at least we think we will have to publicly justify our decisions to confirm moral and social norms. Hence, on the basis of such information which individuals acquire, store, process and act on from the environment decisions are made (Turpin and Marais 2006). This is the fundamental aspect of social cognition that deals with the psychological mechanisms to mediate the individual's responses in social settings and decision making is one of them.

\footnotetext{
${ }^{1}$ Research Scholar, Zakir Husain Centre for Educational Studies, Jawaharlal Nehru University, New Delhi, India *Responding Author

(C) 2016 I A Pramanik; licensee IJIP. This is an Open Access Research distributed under the terms of the Creative Commons Attribution License (http://creativecommons.org/licenses/by/2.0), which permits unrestricted use, distribution, and reproduction in any Medium, provided the original work is properly cited.
} 


\section{Decision Making: A Core Problem of Social Cognition}

The ability to understand and infer other people's feelings, thought and intensions is referred to as social cognition. Based on this understanding of the mental states of others we make prediction about their behavior and adjust our decisions accordingly. Moscowitz (2005) argues that a successful decision making in a social setting depends on our ability to understand the intension, emotions and beliefs of others. Empathy extends social cognition by adding an emotional component to it. Although decision making is one of the everyday activities which seem to generate movement effortlessly, the process is not as easy as it may seem.

The field of social cognition has come to prominence with the rise of cognitive psychology in the late 1960s and now has the dominant approach in the mainstream social psychology. The study of social cognition has been revitalized with the development of computer technology and cognitive science, and turned into an advanced scientific discipline of social cognitive neuroscience (Ochsner \& Lieberman, 2001). Previously, it was believed that social behaviors are influenced by several external factors. But according to modern social cognition, social behavior cannot be determined only by considering the environmental factors which are external to the individual; rather it results from the internal cognitive processes which influence our interpretation of the social context. In simple words, social cognition helps to bridge the gap between inner mental processes and overt behavior of an individual. Decision making is just one of the many areas in which social cognition has a dominant role. Making a decision is a complex cognitive skill which involves perception, attention, memory, thinking, reasoning etc. More than three decades of systematic research on decision making have provided insights $\mathrm{n}$ a variety of issues, but according to Hoch, Kunreuther, and Gunther (2001), many areas of the decision making are yet to be uncovered. Very often information available to us for decision making about a particular social issue are incomplete, ambiguous or contradictory. Now, the question naturally arises, how can we use all these information and arrive at a coherent decision? And also what are the factors that influence our decisions? Here in this paper we try to explore the answers of these core questions about decision making in social cognition.

\section{PROCESS INVOLVED IN DECISION MAKING}

Decision making by definition is the process of preparing an option or a course of action over other alternatives on the basis of given criteria or strategies (Wilson \& Keil, 2001; Wang et al., 2004). In this context, there are different types of decisions that come to mind - it can be decisions about other people, decisions about oneself, decisions that are influenced by other people as well as decisions that are interactive regarding a particular situation. Therefore, every decision that we take usually have many dynamics. Decision making involves deep rooted cognitive tasks including human thoughts, reasoning, past experiences, as well reactions to the external world, which include the possible future orientations, and also the psychological consequences to the decision makers. According to Arnaldo Oliveira (2007) decisions are responses to situations which include three aspects: First, there may be more than one alternative choices or a belief of action under consideration. Second, decision makers can alters or form expectations concerning future events that are often describe in terms of probabilities or degree 


\section{Decision Making: A Core Problem of Social Cognition}

of confidence, and finally, the consequences of a decision that is associated with the probability of success or effectiveness by choosing the best fitted option, that can be assessed in terms of reflecting personal values and current goals. Zachary et al. (1982) stated that there are three constituents in decision making: (a) the decision situation, (b) the decision maker, and (c) the decision process. However, the core cognitive processes of the human brain share the similar and recursive characteristics and mechanisms in decision making process (Wang, 2003; Wang \& Gafurov, 2003; Wang \& Wang, 2004; Wang et al., 2004).

\section{The Rational Model:}

Thinking without biases is called rational thinking. In rational model, decision making is assumed to be rational. Here decision maker analyzes a number of possible alternatives from different scenarios before selecting a choice. By this it means that the individual who decides under certainty have a clear knowledge of the alternatives, know their outcomes, have clear knowledge about their decision criteria, and also posses the ability to integrate discrete information from the environment to make the optimum choice and then to implement it efficiently (Towler, 2010). According to the rational model, the decision making process can be broken down into six steps (Schoenfeld, 2011). After identifying the problem, alternative solutions to the problem are generated. Next, these alternatives are carefully evaluated, and the best suited one is chosen for implementation. The implemented alternative is then again evaluated over time to assure its reliability of effectiveness. It is comes as an effective solution to the problem then the decision is considered to be good, but if difficulties would arise at any stage in the process, recycling may be effected. Thus, from the perspective of perspective of rational model decision making is a logical sequence of alternatives.

\section{The Bounded Rationality Model:}

Herbert Simon $(1982,1997,2009)$ claims that sometimes rationality of an individual for taking a decision is limited by the information they have. The cognitive limitations of mind, pool of relevant and irrelevant information, and the finite amount of time they have to make decisions constrain their work of decision making. He termed it as 'bounded rationality'. Simon states that most people are partly rational, and are irrational in the remaining part of their actions. He extends that "boundedly rational agents experience limits in formulating and solving complex problems and in processing (receiving, storing, retrieving, transmitting) information” (Williamson, 1981, p.553, citing Simon, 1997). Nielsen (2011) pointed out that one version of bounded rationality is the principle of 'satisficing' where decision maker chooses the first alternative that satisfies minimal standards of acceptability without exploring all possibilities. In words of Simon (1997) "Most human decision making, whether individual or organizational, is concerned with the discovery and selection of satisfactory alternatives; only in exceptional cases is it concerned with the discovery and selection of optimal alternatives” (pp. 40-41). In such a case the decision maker, who would like to make the best decision, normally settles for less than the optimal. In his opinion there are two types of people: (a) who has more information and take 


\section{Decision Making: A Core Problem of Social Cognition}

more time to make decisions, and (b) one who has selective information and take decision early. Simon says that all human beings are bounded rational to some extent.

When individual makes satisfying decisions, he/she may use a set of heuristics to guide their decisions. A heuristic is a 'rule of thumb' that can help the decision maker find a solution in a complex and uncertain situation (Moustakas, 1990) for convenience and speed. Heuristics are mental short cuts that reduce the cognitive burden associated with decision making. Shah and Oppenheimer (2008) argued that heuristics reduce work in decision making in several ways. Heuristics offer the user the ability to scrutinize few signals and/or alternative choices in decision making. In addition, heuristics diminish the work of retrieving and storing information in memory; trigger the decision making process by reducing the amount of integrated information necessary in making the choice or passing judgment. People use heuristics in everyday lives. One important and economical heuristic is the representative heuristic (Pachur \& Hertwig, 2006). If in a situation one of two things is recognizable, people will tend to choose the recognized thing to arriving at a decision with the least amount of effort or information (Goldstein \& Gigerenzer, 2002; Hilbig \& Pohl, 2008). According to Hilbig and Pohl (2008) people often use additional information when utilizing the representative heuristic because they do not completely rely on recognition alone in decision making. Another highly used heuristic is the availability heuristic (McKelvie, 2000; Redelmeier, 2005). In it people are inclined to retrieve information that is most readily available in making a decision. Redelmeier (2005) explains that heuristics are beneficial as they are cognitively economical, but one has to be careful in determining when heuristics need to be over-ridden in favor of more comprehensive decision making approaches.

\section{The Attribution theory}

Another cognitive explanation of decision making is the Attribution Theory. This theory originated with Julian Rotter and Fritz Heider's work and Wiener extends it over the last thirty years (Weiner, 1972; Weiner, 2000). Attribution is a concept by which individuals explain the causes of behavior. According to this theory depending on certain specific attributes people take decisions in their everyday life. This theory works to explain how an individual's perceived reasons for past success and failure contribute to their current and future motivation and success of an event (Weiner, 1974). It is considered that a complex attributional analysis of situations from the individual's point of view is very important in establishing a coherent decision in various contexts. The theory revolves around four causal attributions: ability, effort, task difficulty, and luck. Each is characterized as stable or unstable, internal or external, and controllable or uncontrollable (Weiner, 1986). The extent to which a person tends to use the same combination of these causes over time is known as attributional style (Metalsky \& Abramson, 1981). The assumptions of this theory is that whether the participants attribute causes of their decisions to either internal causes such as ability and effort, and/or external factors such as nature of the task, competitors' strategy and luck (Oghojafor et al., 2012). However, these causal dimensions are not static. They are changeable in meaning across different situations and across different individuals' perceptions of the properties of the cause. On the contrary, the 
fundamental attribution errors are the tendency of an individual to underestimate the influence of external factors and overestimate the influence of internal factors when making decision. Another one is self-serving bias, which is the tendency for individuals to attribute their own successes to internal factors while putting the blame for failures on external factors.

\section{FACTORS INFLUENCED DECISION MAKING}

In this section, we attempt to address some of the social cognitive aspects of decision-making. There are several factors that influence our decisions, such as past experiences (Juliusson, Karlsson \& Garling, 2005), cognitive biases (Stanovich \& West, 2008), age and individual differences (Bruin, Parker \& Fischoff, 2007), belief in personal relevance (Acevedo \& Krueger, 2004), information overload, illusion of knowledge, heuristics and an escalation of commitment etc. It is important to know the factors that influence our decisions, because it helps to understand what may impact the outcomes and why a particular decision is made. Social cognition involves the perception, interpretation and processing of social information that underlies social interactions and includes emotion, social perception, social knowledge and attribution bias (Penn et al., 2005). As we know that heuristic is one such phenomena that serves as a framework in which satisfactory decisions are made quickly and with ease (Shah \& Oppenheimer, 2008). Thus, researchers of social cognition are concerned with that social realm which involves its many hidden and subjective features.

Further, past experiences can also impact future decision making. Juliusson, Karlsson, and Garling (2005) claimed that on the basis of past experiences people infer in future. If there was a positive result in past, then people are more likely to decide in a similar way, if they are given a similar situation. Again, in real life when one encountered a sudden event like an accident for the first time, people accumulate this information as knowledge or believe in their memory. These accumulated knowledge and beliefs are known as cognitive structure. Our mind consists of vast amount of such knowledge and believes; and we expect something that confirms these believes. Because of expectancy people only focus on those aspects that they want to. Thus, here the decision is influenced by subsequent process of information. On the other hand, people sometimes tend to avoid repeating past mistakes if the consequences of the decision have been wrong (Sagi \& Friedland, 2007). Thus, it is significant to some extent that future decisions made based on past experiences is not necessarily the best decisions always. This concept is most applicable in business market, where anything can change any moment. Here, highly successful people do not make investment decisions based on past sunk outcomes; rather prefer to examine the choices with no regards of past experiences (Juliusson et al., 2005).

In addition to past experiences, there are several other cognitive biases that influence decision making. Such as thinking patterns based on observations and generalizations that may lead to memory errors, inaccurate judgments, and faulty logic (Evans, Barston \& Pollard, 1983; Stanovich \& West, 2008). Apart from that belief bias (the over dependence on prior knowledge in arriving at decisions); hindsight bias (people tend to readily explain an event as inevitable, 


\section{Decision Making: A Core Problem of Social Cognition}

once it has happened); omission bias (people have a propensity to omit information perceived as risky); and confirmation bias (people observe what they expect in observations) are some important cognitive biases (Stanovich \& West, 2008). Moreover, cognitive biases influence people by causing them to over rely on their beliefs, expected observations and previous knowledge, while dismissing information or observations that are novel, without looking at the bigger picture. All in all these cognitive biases can influence our judgement and sometimes may lead to poor decisions. These cognitive biases in contrary enable individuals to make efficient decisions with assistance of heuristics phenomenon (Shah \& Oppenheimer, 2008).

A major part of decisions are influenced by an escalation of commitment and sunk outcomes. Juliusson et al. (2005) claimed that people make decisions based on an irrational escalation of commitment, that is, individuals invest larger amount of time, money, and effort into a decision to which they feel committed. Again when people feel responsible for the sunk costs, time, money, and effort spent on a project, they usually tend to continue to make risky decisions. As a result, decision making may at times be influenced by the individual's position in the situational context and relationship he/she shared (Juliusson et al., 2005).

There are some individual differences which may also influence decision making. Researchers (Finucane et al., 2005; Bruin, Parker, \& Fischoff, 2007) have indicated that age, socioeconomic status, and cognitive abilities influences decision making. Finucane et al. (2005) state that cognitive functions decline with age, as a result decision making performance may decline as well. In addition, older people may be overconfident regarding their ability to make decisions, which inhibits their ability to apply strategies (Bruin et al., 2007). According to Bruin et al. (2007) people from lower socio-economic status groups may have less access to education and resources, which may make them more susceptible to experiencing negative life events, often beyond their control; and also because of lack of information very often these people may make poorer decisions. Along with above another important factor in decision making is the belief in personal relevance. When people believe that what they decide is the only thing that matters, then usually they are more likely to make a more accurate and unbiased decision (Acevedo \& Krueger, 2004).

\section{Cognitive dissonance theory:}

In cognitive dissonance theory Leon Festinger (1962) talked about pre-decision information processing where the individual is concerned about the pros and cons of a chosen alternatives. He proposed that we hold many cognitions, opinions or beliefs on self, personal conduct and the world as well. These beliefs are related either in a state of consonance or dissonance. A state of consonance is marked by consistency, whereas dissonance is referred to inconsistency. The central tenet of this theory is that people have an inner need to ensure their beliefs and attitudes in consistent to maintain harmony (consonance) and avoid disharmony (dissonance). The goal of the decision process is to choose that particular alternative(s) to avoid discomfort which arises due to dissonance. Therefore, when there is any discrepancy between beliefs or opinions, people 
are motivated to make necessary changes in their decision to reduce or eliminate the discomfort (dissonance) as the experience of dissonance is unpleasant, and achieve consonance (Festinger, 1957).

\section{CONCLUSION}

The interest in the study of decision-making has been widely shared in various disciplines because it is a fundamental entity of social life. It is an important area of research in the field of general psychology, social psychology, cognitive psychology, organizational behavior, industrial psychology; even many other interdisciplinary field of study like cognitive science, neuroscience, and management. Understanding the process by which individuals make decision is important to know the complexity of the whole process, which further helps to know the different factors that influence the outcomes. Some of those factors are past experiences, cognitive biases, age and individual differences, beliefs in personal relevance, and an escalation of commitment. As we come to know from the above discussion that there are different cognitive processes that are involved in decision making and also all those social and cognitive factors that influence our decision. It can be concluded that many important aspects of social cognition not only helps us to know what are involved in making decisions, but also helps us to interpret the world around us more effectively.

As it says any new idea or product never ever comes out ex nihilo. It uses the knowledge which is already exist and modify the old or comes with a completely new one while dealing the changing circumstances. In a single paper it is impossible to put light in all the theories in decision making that are existing. Although the above narratives are very selective and precise, but it is sufficient to indicate how far the research has progressed in the particular area. Herewith it is need to speculate the future prospect to know how long it will continue to produce history. To answer this one need to examine what researchers have accomplished so far, and notice the gaps in the knowledge base that need to fill. It is needed to do more research on decision making in the realm of social cognition and comes up with better theories which would expand the horizon by providing scope to the future researchers.

\section{REFERENCES}

Acevedo, M., \& Krueger, J. I. (2004). Two egocentric sources of the decision to vote: The voter's illusion and the belief in personal relevance. Political Psychology, Vol. 25, Iss.1, pp.115-134.

Bruin, W. B., Parker, A. M., \& Fischhoff, B. (2007). Individual differences in adult decisionmaking competence. Journal of Personality and Social Psychology, Vol. 92, Iss. 5, pp. 938-956.

Evans, J. S. B., Barston, J. L., \& Pollard, P. (1983). On the conflict between logic and belief in syllogistic reasoning. Memory \& cognition, Vol. 11, Iss. 3, pp. 295-306.

Festinger, L. (1957). The theory of Cognitive Dissonance. Stanford, CA: Stanford University Press. 
Finucane, M. L., Mertz, C. K., Slovic, P., \& Schmidt, E. S. (2005). Task complexity and older adults' decision-making competence. Psychology and Aging, Vol. 20, Iss. 1, pp. 71-84.

Goldstein, D. G., \& Gigerenzer, G. (2002). Models of ecological rationality: The recognition heuristic. Psychological Review, Vol. 109, Iss. 1, pp. 75-90.

Hilbig, B. E., \& Pohl, R. F. (2008). Recognition users of the recognition heuristic. Experimental Psychology, Vol. 55, Iss. 6, pp. 394-401.

Hoch, S. J., Kunreuther, H. C., \& Gunther, R. E. (2001). Wharton on making decisions. New York: John Wiley \& Sons, Inc.

Jullisson, E. A., Karlsson, N., Garling, T. (2005). Weighing the past and the future in decision making. European Journal of Cognitive Psychology, Vol. 17, Iss. 4, pp. 561-575.

McKelvie, S. J. (2000). Quantifying the availability heuristic with famous names. North American Journal of Psychology, Vol. 2, Iss. 2, pp. 347-357.

Metalsky, G. I., \& Abramson, L. Y. (1981). Attributional Styles: Toward a Framework for Conceptualization and Assessment. In P. C. Kendall \& S. D. Hollon (Ed.), Assessment Strategies for Cognitive-Behavioral Interventions (pp. 15-58). New York: Academic Press.

Moscowitz, G. B. (2005). Social cognition: Understanding self and others. New York: Guilford Press.

Moustakes, C. (1990). Heuristic research: Design, methodology, and application. Newbury Park, CA: Sage.

Nielsen, H. (2011). Bounded rationality in decision making. Dobbs Ferry, NY: Manchester University Press.

Ochsner, K. N. \& Lieberman, M. D. (2001). The emergence of social cognitive neuroscience. American Psychologist, Vol. 56, Iss. 9, pp. 717-734.

Oghojafor, B. E. A., Olayemi, O. O., Oluwatula, O. O. \& Okonji, P. S. (2012). Attribution Theory and Strategic Decisions on Organizational Success Factors. Journal of Management and Strategy, Vol. 3, Iss. 1, pp. 32-39.

Oliveira, A. (2007). A Discussion of Rational and Psychological Decision-Making Theories and Models: The Search for a Cultural-Ethical Decision-Making Model. (EJBO) Electronic Journal of Business Ethics and Organization Studies, Vol. 12, Iss. 2, pp. 12-17.

Pachur, T, \& Hertwig, R. (2006). On the psychology of the recognition heuristic: Retrieval primacy as a key determinant of its use. Journal of Experimental Psychology, Learning, Memory, and Cognition, Vol. 32, Iss. 5, pp. 983-1002.

Penn, D. L., Addington, J. \& Pinkham, A. (2005). Social cognitive impairments. In J. A. Lieberman, T. S. Stroup \& D. O. Perkins (Ed.), American Psychiatric Association Textbook of Schizophrenia. Washington, DC: American Psychiatric Publishing Press.

Redelmeier, D. A. (2005). The cognitive psychology of missed diagnosis. Annals of Internal Medicine, Vol. 142, Iss. 2, pp. 115-120.

Schoenfeld, A. H. (2011). How we think: A theory of goal-oriented decision making and its educational applications. New York: Routledge.

Sagi, A., \& Friedland, N. (2007). The cost of richness: The effect of the size and diversity of decision sets on post-decision regret. Journal of Personality and Social Psychology, Vol. 93, Iss. 4, pp. 515-524.

Shah, A. K., \& Oppenheimer, D. M. (2008). Heuristics made easy: An effort-reduction framework. Psychological Bulletin, Vol. 134, Iss. 2, pp. 207-222.

Simon, H. A. (1982). Models of bounded rationality. Cambridge, MA: MIT Press. 
Simon, H. A. (1997). Models of bounded rationality: Empirically grounded economic reason. Cambridge, MA: MIT Press.

Simon, H. A. (2009). Economics, bounded rationality, and the cognitive revolution. Northampton, MA: Edward Elgar Publishing.

Stanovich, K. E., \& West, R. F. (2008). On the relative independence of thinking biases and cognitive ability. Journal of Personality and Social Psychology, Vol. 94, Iss. 4, pp. 672695.

Towler, M. (2010). Rational decision making: An introduction. New York: Wiley.

Turpin, S. M., \& Marais, M. A. (2006). Decision-making: Theory and practice.ORiON: The Journal of ORSSA, Vol. 20, Iss. 2, pp. 143-160.

Wang, Y. (2003). On cognitive informatics. Brain and Mind: A Transdisciplinary Journal of Neuroscience and Neurophilosophy, 4, Iss. 2, pp. 151-167.

Wang, Y., \& Gafurov, D. (2003). The cognitive process of comprehension. In Proceedings of the $2^{\text {nd }}$ IEEE International Conference on Cognitive Informatics (ICCI'03) (pp. 93-97), London, UK.

Wang, Y., \& Wang, Y. (2004). Cognitive informatics models of the brain. IEEE Transactions on Systems, Man, and Cybernetics (C), Vol. 36, Iss. 2, pp. 203-207.

Wang, Y., Wang, Y., Patel, S., \& Patel, D. (2004). A layered reference model of the brain (LRMB). IEEE Transactions on Systems, Man, and Cybernetics (C), Vol. 36, Iss. 2, pp. 124-133.

Weiner, B. (1972). Theories of Motivation: From Mechanism to Cognition. Chicago: Markham Publishing Company.

Weiner, B. (Ed.). (1974). Cognitive Views of Human Motivation. New York: Academic Press, Inc.

Weiner, B. (1986). An attributional theory of motivation and emotion. New York: SpringerVerlag.

Weiner, B. (2000). Intrapersonal and interpersonal theories of motivation from an attributional perspective. Educational Psychology Review, Vol. 12, Iss. 1, pp. 1-14.

Wilson, R. A., \& Keil, F. C. (2001). The MIT Encyclopedia of the Cognitive Sciences. MIT Press.

Williamson, E. Oliver (1981), The Economics of Organization: The Transaction Cost Approach. The American Journal of Sociology, Vol. 87, Iss. 3, pp. 548-577.

Zachary, W., Wherry, R., Glenn, F., Hopson, J. (1982). Decision situations, decision processes, and decision functions: Towards a theory-based framework for decision-aid design. In Proceedings of the 1982 Conference on Human Factors in Computing Systems. 